\title{
Project Evaluation: A Mixed-Method Study into Dilemmas in Continuation Decisions
}

\author{
Arviansyah \\ University of Twente \\ a.arviansyah@utwente.nl \\ Yvette ter Halle \\ University of Twente \\ y.terhalle@student.utwente.nl
}

\author{
Ton Spil \\ University of Twente \\ a.a.m.spil@utwente.nl \\ Jos van Hillegersberg \\ University of Twente \\ j.vanhillegersberg@utwente.nl
}

\begin{abstract}
Project evaluations are highly crucial for organizations to manage their information systems and technology project portfolios. This study postulates equivocal situations as the source of dilemmas hindering stakeholders to achieve proper evaluation and purposeful decisions. We examine three factors that are conceived to have high association with equivocal situations when evaluating IS/IT projects; Challenges in project management, Different frames of reference and Lack of evaluation data. The developed model is tested using a survey data of IS/IT professionals through PLS. We find the three factors are significantly affecting the occurrence of equivocal situations with the highest contribution come from the Challenges in project management. Multi-group examinations reveal distinct impacts of the three factors within public versus private sector and high versus low projects in the project evaluation ladder. Post hoc interviews suggest several interesting points especially on how to cope with equivocal situations.
\end{abstract}

\section{Introduction}

Failures and their related cost in the "Software Hall of Shame" depicted by Charette [1] paint a bleak picture of IS/IT projects in many organizations. IS/IT projects are often seen as disruptions in businesses that could spell disaster for organizations. The distinctiveness of IS/IT projects compared to other types of projects are known by (1) the difficulty in dealing with the volatilities of requirement and scope from numerous stakeholders, (2) the lack of visibility of the projects resulting problems to estimate project completion, and (3) the difficulty in defining precise benefits [2-4]. Compared to the typical IS/IT projects, large-scale IS/IT projects are recognized by their (1) longer duration, (2) larger requisite resources, (3) more complex IS/IT products, and (4) more involvement of multiple stakeholders [5]. Moreover, the "black swan" IS/IT projects are associated with the occurrence of rare and unpredictable events within project execution which often destructive [6]. These events may be caused by the lack of experience to estimate the IS/IT project risk and the failure to anticipate the interconnectedness of IS/IT projects [6]. The examples of large-scale and "black swan" IS/IT projects show projects which are seemed to take on a life of their own and are often deemed to fail eventually [6-8].

Evaluations are promoted to identify issues within project management and obtain early warnings based on the projects' current status; thus, they provide insight into which strategy will be well-positioned to accomplish the IS/IT investment objectives [9]. Farbey, Land and Targett [10] described IS/IT project evaluation as "a process, or group of parallel processes, which take place at different points in time or continuously, for searching and for making explicit, quantitatively or qualitatively, all the impacts of an IT project and the programme and strategy of which it is a part" (p. 190). Evaluation are beneficial since they allow organizations to control projects and to compare the merit and worth of different projects competing for limited resources [11]. Through the use of appraisal methods and techniques, evaluations allow decision-makers to benchmark and define costs, benefits, risks and the implications of IS/IT projects [12].

However, prior studies reported evaluations of IS/IT projects are challenging despite their importance to make purposeful decisions. Past studies have highlighted difficulty in evaluating progress of the projects $[13,14]$. For instance, examination of project reports by Snow \& Keil [15, 16] indicated information related to projects' execution often raises ambiguity. Organizations are 
suspected to have difficulty applying evaluations in practice. Information associated with the project has aroused disagreement among decision-makers and encouraged negotiation regarding the next course of action $[17,18]$. Decision-makers may interpret the projects' worthiness from unclear indications and get trapped in dilemmatic situations due to a lack of clarity and understanding of the situations. Thus, decisions are often relied upon personal experiences and judgments [19] and frequently made in so-called equivocal situations.

Equivocality as the heart of equivocal situations is conceived as the important determinant in affecting the continuation decisions. The effects of equivocality on escalation and delayed abandonment are substantiated by experiments conducted in the field of psychology [20, 21]. Arguably, reducing the equivocal situations in project evaluations is desirable to make improved and purposeful decisions as well as to reduce the chance of improper decisions. By subscribing to Bowen's Decision Dilemma theory we follow the conjecture that continuation decisions of IS/IT projects are seen more as dilemmas rather than errors of decision-making which occur when decision-makers have to struggle deciding the projects' next course of action in the face of problematic equivocal situations. Despite support from several studies showing the importance of equivocality in affecting continuation decisions [22] the causes of equivocality are not well recognized.

The studies examining the causes of equivocal situations in IS/IT projects is lacking. Likewise, empirical support to substantiate the relations between the causes and the equivocal situations is still limited. We hardly know what the important causes are. Specifically, we endeavor to address the following research question:

What are the salient causes driving equivocal situations in IS/IT project evaluations and what are the insights that decision-makers need to take into account in continuation decisions?

To glean insights into equivocal situations and their causes during project evaluations we develop a theoretically grounded research model built upon extant studies and utilize a mixed-method research combining quantitative and qualitative methods. We aim to reveal the salient drivers of equivocal situations and provide early evidence of equivocal situations within project evaluations.

\section{Theoretical foundation and hypotheses development}

The term 'equivocal information' was introduced by Bowen [23] as information for which multiple (positive or negative) interpretations can be constructed. Based on the Decision Dilemma theory, equivocal information may lead to escalation [23]. When decisions are required in equivocal conditions, project escalations are likely to occur, caused by the belief that commitment of additional resources are economically prudent. The occurrence might also be caused by curiosity to learn or to understand the equivocal situations by means of the upcoming information. It is expected that completing the endeavor will eventually deliver benefits [24]. Escalation occurs when decision-makers assume the information is inadequate and suggest that additional investments will not fulfill expectations. To abandon the endeavor, unequivocal negative information is required; this in order to convince decision-makers the projects are no longer beneficial, implying that even additional resources would not bring success [23].

We defined equivocal situations in IS/IT project evaluations based on our prior literature review as the state when decision-makers or evaluators encounter a lack of clarity and confusion in deciding upon the continuation of a project, which occur when lack of knowledge or diverse knowledge exists in regard to information surrounding the project, especially its past performance and future attainment.

In this study, the Equivocal situation (ES) construct refers to the extent to which evaluation of the project is hampered by equivocality. We highlighted the characteristics of equivocal situations that can serve as indicators. The equivocal situations are indicated by (1) the lack of clarity of project condition and confusion toward the next course of action; (2) the existence of different interpretations among decision-makers concerning information surrounding the projects; and (3) the indeterminacy of analyzed data to base the decision on. Conceivably, these indicators show the extent of equivocality in the project evaluations. Next, we adapted items from [25], [26], [27] and [28] to align our indicators with the extant studies.

Furthermore, extant studies indicated several problems related to equivocal situations. For instance, lack of clarity about projects' success and failure criteria, vagueness of project charter, or ambiguity of information surrounding the projects execution $[14,15,29]$. These problems seem to play important roles in driving the dilemma in project evaluations and hindering purposeful decision- 
making. We consolidated the identified problems from earlier studies and categorized them into factors posited as the causes of equivocal situations that occur in project evaluations. These factors are described and the hypotheses are developed as follows:

Challenges in project management (CPM) refers to the extent to which the IS/IT project encounters substantial management challenges. Project management practices are requisite to improve estimation of the risks and deterministic for the performance of IS/IT projects $[6,30]$. The practices suggest guidelines for successfully handle the projects and avoiding pitfalls during project executions. Erroneously practices are shown to be destructive to the projects leading to improper strategy to accomplish the justified IS/IT investment [31]. For instance, vague project charters in which the projects are planned and defined could lead to equivocal situations [14]. The identified issues within this category are problems in the project planning (CPM1) and monitoring (CPM2), problems in communication among people in the project management structure (CPM3), and problems related to the clarity of the project charter (CPM4) [32, 33]. We hypothesize that (H1): Challenges in project management is positively associated with the occurrence of an Equivocal situation.

Different frames of reference (DFR) refers to the extent to which evaluators/decision-makers have diverse viewpoints when evaluating the project. Decision-makers or evaluators are commonly composed of people from different stakeholders of the projects. They may consist of people from internal and external of the organization who come from different functional areas and/or managerial levels. They work as a group endeavoring to evaluate and decide the continuation of the projects. Arguably, different perspectives and opinions may exist due to different interest and frames of references [14, 34]. Not being able to deal with these issues the condition may promote equivocal situations and deteriorate decision-making [35-38]. The identified issues within this category are the problem of decision-makers having diverse backgrounds (DFR1) and the problem of decision-makers having uncomplimentary skills or abilities (DFR2) when conducting evaluations [39, 40]. Thus, we hypothesize that (H2): Different frames of reference is positively associated with the occurrence of an Equivocal situation.

Lack of evaluation data (LED) refers to the extent to which evaluators/decision-makers use data surrounding the project to support decision-making. Proper evaluations necessitate continuous data retrieval of the projects execution. The data surrounding the projects is imperative to support decision-making. Lack of requisite data can lower the evaluation quality, which in turn may reduce confidence in decision-making. The lack of data surrounding the project is argued to increase equivocal situations that often lead to decision of escalation; especially data or information on the projects past performance [41]. Prior studies have highlighted the lack of data in term of types, quantity and quality as well as validity and reliability may increase the level of equivocality and worsen the situations [23, 36, 42]. The identified issues within this category are the problems with accuracy (LED1) and availability (LED2) of the requisite data as well as the level of detail of the data (LED3) [43, 44]. Therefore, we hypothesize that (H3): Lack of evaluation data is positively associated with the occurrence of an Equivocal situation.

Based on the literature review and our discussion of sources for equivocality, we present a model of an Equivocal situation as a dependent variable which is affected by three independent variables. Figure 1 illustrates the research model.

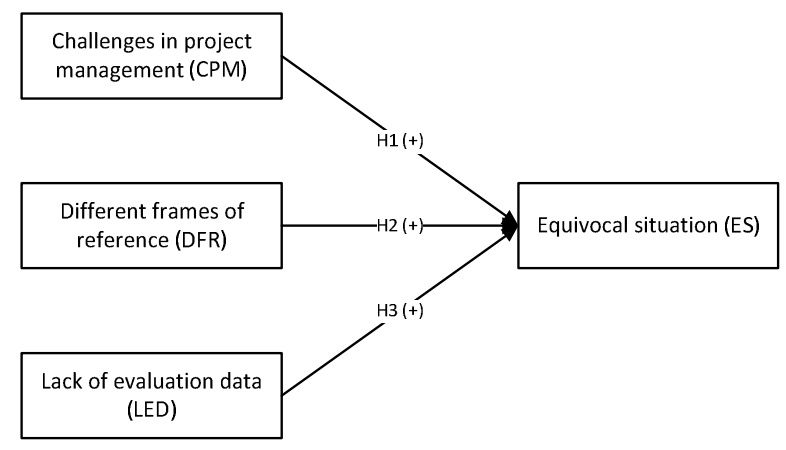

Figure 1. Research model

\section{Research design}

We constructed the measurement items by adopting scales that were relevant within our constructed factors. The scales were reworded to be suitable within our research domain. Prior to data collection, two rounds of Q-sorting exercises were held. The result of an average "hit ratios" of 86 per cent, an average raw agreement of 85 per cent, and an average Kappa of 83 per cent showed that the items have adequately tapped to our constructed factors [45]. After ensuring substantive validity of the constructs we continued the empirical part by developing the questionnaire based on the result of the Q-sorting exercises. Table 1 shows the measurements of the developed constructs. 
Table 1. Measurements of the constructs

\begin{tabular}{|c|c|}
\hline$\overline{E S 1}$ & $\begin{array}{l}\text { The project status or condition was hard } \\
\text { to ascertain caused by different } \\
\text { interpretations among decision-makers } \\
\text { toward information surrounding the } \\
\text { project }\end{array}$ \\
\hline ES2 & $\begin{array}{l}\text { Decision-makers lacked clarity and } \\
\text { understanding of the condition of the } \\
\text { project and thus were confused } \\
\text { concerning the next course of action }\end{array}$ \\
\hline ES3 & $\begin{array}{l}\text { It was problematic to analyze the } \\
\text { condition of the project since } \\
\text { insufficient objective data was available } \\
\text { to base the decisions on }\end{array}$ \\
\hline CPM1 & $\begin{array}{l}\text { The project did NOT adequately set out } \\
\text { project milestones }\end{array}$ \\
\hline CPM2 & $\begin{array}{l}\text { Senior management did NOT } \\
\text { adequately control the project in order } \\
\text { to keep it on track }\end{array}$ \\
\hline CPM3 & $\begin{array}{l}\text { Ineffective communication among } \\
\text { people in the project management } \\
\text { structure }\end{array}$ \\
\hline CPM4 & $\begin{array}{l}\text { The project charter as the basis for } \\
\text { managing the project was vague }\end{array}$ \\
\hline$\overline{\text { DFR1 }}$ & $\begin{array}{l}\text { The decision-makers had different } \\
\text { backgrounds }\end{array}$ \\
\hline DFR2 & $\begin{array}{l}\text { The decision-makers had skills and } \\
\text { abilities that complement each other } \\
\text { (reverse) }\end{array}$ \\
\hline LED1 & $\begin{array}{l}\text { The data used were accurate enough to } \\
\text { evaluate the project (reverse) }\end{array}$ \\
\hline LED2 & $\begin{array}{l}\text { It is difficult to evaluate the project } \\
\text { effectively because some of the data } \\
\text { needed were NOT available }\end{array}$ \\
\hline LED3 & $\begin{array}{l}\text { The data were at an appropriate level of } \\
\text { detail to evaluate the project (reverse) }\end{array}$ \\
\hline
\end{tabular}

By using an online tool distributed as a web link, participants were asked to recall a recent review or evaluation of a challenged IS/IT project they involved in and to keep this one project in mind throughout the questionnaire. The equivocal situations in project evaluations were assessed by asking the participants the extent of the occurrence for each of the aforementioned characteristics of equivocal situations. The factors posited to drive equivocal situations were assessed as well. The 7point Likert scales ranging from (1) Not at all/ Strongly disagree and (7) Very great extent/Strongly agree were used to measure the constructs.

The invitations to participate were sent through several relevant LinkedIn groups and organizations of IS/IT professionals. Calculating Cohen's power of regression analysis at $\alpha=0.05$ with a medium effect size $(\mathrm{f} 2=0.15$ ) and a power level of 0.8 , a sample of at least 84 was needed [46]. Based on report of the survey's web link around 246 people accessed the survey and 108 participants (44\%) completely filled in the survey.

Participants of the survey consist of senior managers of IS/IT - CIO (22\%), project managers (21\%), and IS/IT managers (19\%). The rest includes non-senior or non-managers of IS/IT and other roles such as consultants, auditors, etc. Profile of the chosen projects: $19 \%$ was suffering total and substantial abandonment. 51\% was categorized as escalated, $26 \%$ was continued as planned and another 5\% was answered as "other". $69 \%$ was larger and $71 \%$ was longer compared to other IS/IT projects undertaken by the organizations. $62 \%$ to certain extent suffered from over budget, $78 \%$ was behind schedule and $69 \%$ was lacking expected requirements or specifications.

\section{Analysis and result}

To test the measurement model and to analyze the direction and strength of each relationship we utilized PLS which is well suited for theory building and prediction as well as handling mixed reflective and formative measures [47]. SmartPLS version 2.0 (M3) was used to run the PLS analysis [48].

Equivocal situations were assessed based on values of indicator loadings, the average variance extracted (AVE), composite reliability, and Cronbach's alpha. All values are higher than the suggested threshold $(0.70,0.50,0.70$, and 0.70 , respectively) $[49,50]$. A good quality of measurements can be derived from these assessments.

Since the three factors were using formative indicators, an examination of the construct correlations matrix and variance inflation factor (VIF) were necessary to detect the threat of multicollinearity. None of the correlations between constructs are above 0.71, which provides discriminant validity of the constructs [51]. The result for VIF was below 3.3 which suggest no threat of multicollinearity $[49,50,52]$. Furthermore, the formative measurements were examined by running the PLS algorithm to obtain their weights and running the bootstrap to obtain their statistical significance. The number of bootstrap samples was set to 5000 and the number of cases was equal to the original sample [49]. Figure 2 visualizes the PLS result and provides the weights of each items and their statistical significance. CPM3, LED1 and LED3 were reported to be not significant. However, the outer loadings of these items were $0.7,0.45$ and 0.45 
respectively and significant. These items then were retained based on [46].

Figure 2 also shows the path coefficients and their significance within the structural model. This specifies that all the hypotheses are supported. The resulted $\mathrm{R}^{2}$ was 0.45 , which suggests a fairly moderate level [49]. Moreover, the Stone-Geiser Q2 for Equivocal situation was 0.29 , which indicates the overall model's predictive relevance and an acceptable model performance [49]. Moreover, the effect size $\mathrm{f}^{2}$ and $\mathrm{q}^{2}$ for CPM, DFR and LED are shown in Table 2. CPM has relatively moderate to strong effect size compare to DFR and LED. Likewise, CPM has fairly moderate degree of predictive relevance compare to DFR and LED.

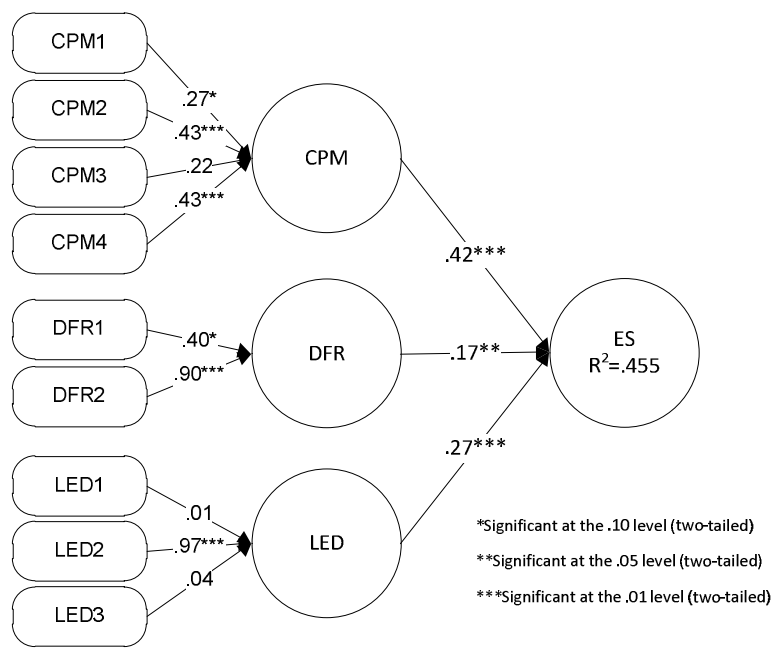

Figure 2. PLS result $(\mathrm{N}=108)$

The PLS result substantiates the impact of CPM, DFR and LED toward an equivocal situation (ES). Since the independent variables were treated as formative construct, impact of individual indicators on an equivocal situation (ES) can be further determined by evaluating their path weights. Thus, the importance of each indicators associated to the latent constructs are shown by the values of weights. The PLS result shows that (start from the highest value): (1) within the Challenges in project management (CPM), the identified problems which are highly associated with equivocal situations in project evaluations are the inadequate control of senior management (CPM2) and the unclear or vague project charters (CPM4). Additionally, projects which do not adequately set out project milestones (CPM1) will lead to equivocal situations. Within the Different frames of reference (DFR), the identified problems which are highly associated with equivocal situations in project evaluations is the lack of complementary skills and abilities among decision- makers (DFR2) when conducting evaluations. Additionally, the different background among decision-makers also contributes significantly to equivocal situations (DFR1), e.g., different functional department. Within the Lack of evaluation data (LED), the identified problem which highly associated with equivocal situations in project evaluations is the unavailability of essential data to support decision-making (LED2).

Table 2. $f^{2}$ and $q^{2}$ effect size

\begin{tabular}{|l|l|l|}
\hline & $\mathrm{f}^{2}$ & $\mathrm{q}^{2}$ \\
\hline CPM & 0,23 & 0,11 \\
\hline DFR & 0,03 & 0,01 \\
\hline LED & 0,11 & 0,05 \\
\hline
\end{tabular}

\subsection{Post hoc: multi-group analysis}

We conducted multi-group analysis by separating the samples into two groups. First, we constructed two groups of public and private sectors based on the industry. Organizations within public sector include education, government, healthcare and non-profit. The rest of the industry is considered as private sector. Prior research of information systems in public and private sectors reported several differences in managing IS/IT projects; hence, these influence the evaluations and the decision-making of the projects. For instance, differences in measuring output or productivity and performance might lead to different manner in decision-making [53]. There are several limitations in the public sector that could lead to different equivocality problems during project evaluations and decision-making, such as divided authority over IS/IT projects, involvement of multiple stakeholders with competing goals, and interrelated internal process [54].

Second, we constructed two groups of high and low project evaluation ladder based on the taxonomy of IS applications [55]. Project evaluation ladder refers to the different types of IS applications that have different complexity and difficulty when deploying the evaluations [55]. Evaluating high ladder projects are posited to be more experimental and judgmental processes which conceivably have a distinct set of problems leading to equivocal situations [55]. The group of high evaluation ladder includes projects which were aiming for business transformation, strategic system, and new service or product development. The group of low evaluation ladder includes projects which did not have the aforementioned purposes, such as projects aiming for 
direct value added system, automation, or mandatory changes.

We found several interesting points. First, CPM3 and CPM4 significantly had a strong contribution to CPM construct in the public sector, but not CPM1 and CPM2. Conversely, CPM1 and CPM2 had a strong contribution to $\mathrm{CPM}$ construct in private sector, but not CPM3 and CPM4 (although CPM2 was slightly below the significance level of 0.1 ). It seems that the ineffective communication within people in project management structure (CPM3) and the vagueness of project charter (CPM4) are contributing particularly and have greater impact to the equivocal situations in project evaluations occurred within the public sector compare to the private sector. On the other hand, equivocal situations caused by the Challenge in project management in private sector are more concerned with the project planning and control; these are the inadequately set out project milestone (CPM1) and inadequate devotion of senior management to keep the project on track (CPM2).

Second, within the Different frames of reference construct, the different background of decisionmakers (DFR1) was not significant in the public sector. Equivocal situations within the public sector are solely attributed to the lack of complementary skill and abilities among decision-makers (DFR2) instead of caused by different background of the decision-makers (DFR1).

Third, examination of the groups of high and low project evaluation ladder revealed, intriguingly, comparative results. CPM3 and CPM4 were significant in low ladder projects but not in the high ladder projects. Conversely, CPM1 and CPM2 were significant within high ladder projects but not in the low ladder projects. Likewise, DFR1 was not significant within the low ladder projects. Additionally, LED2 was consistently significant across groups. Table 3 summarizes the findings.

\section{Table 3. Multi-group analysis}

\begin{tabular}{|l|l|l|l|l|}
\hline & $\begin{array}{l}\text { Public } \\
(\mathrm{N}=32)\end{array}$ & $\begin{array}{l}\text { Private } \\
(\mathrm{N}=76)\end{array}$ & $\begin{array}{l}\text { Low } \\
(\mathrm{N}=49)\end{array}$ & $\begin{array}{l}\text { High } \\
(\mathrm{N}=59)\end{array}$ \\
\hline CPM1 & $-0,22$ & $0,60^{* *}$ & 0,17 & $0,44^{*}$ \\
\hline CPM2 & 0,19 & $0,36^{*}$ & 0,26 & $0,48^{* *}$ \\
\hline CPM3 & $0,44^{* *}$ & 0,16 & $0,38^{* *}$ & 0,13 \\
\hline CPM4 & $0,78^{* * *}$ & 0,21 & $0,47^{* *}$ & 0,36 \\
\hline DFR1 & 0,32 & $0,54^{*}$ & 0,18 & $0,71 * * *$ \\
\hline DFR2 & $0,93^{* * *}$ & $0,85^{* * *}$ & $0,98^{* * *}$ & $0,71 * * *$ \\
\hline $\begin{array}{l}\text { Bootstrapping results }(\mathrm{n}=5000) \\
\text { *Significant at the } 0.10 \text { level } * * \text { Significant at the } 0.05 \text { level } \\
* * * \text { Significant at the } 0.01 \text { level (all two- tailed) }\end{array}$ \\
\hline
\end{tabular}

\subsection{Post hoc: interview analysis}

Around 42 per cent of participants in the survey were willing to discuss their responses further. Hence, post hoc examinations of the survey responses were viable to gain additional insights concerning the relationships among constructs. Explorations on how practitioners cope with the equivocal situations were warranted as well. Based on the participants' responses in the questionnaires, we obtained six interviews with the informants who were involved in the project evaluations and had experience confronting with equivocal situations at the time of evaluations. Three projects were categorized as escalated (i.e., continue with additional resources or continue with reduction) and another three were categorized as terminated (i.e., substantial abandonment or redirection). A mix of informants within the categories of escalated and terminated projects was expected to provide a wide range of insights on the emergence of equivocality and its impact on the project decisions as well as how they coped with the equivocal situations during project evaluations. Thus, we elaborated more on the problems they had and the way they handled them during our discussions. We were able to elicit several interesting points from these post hoc interviews.

First, the vagueness of project charters (CPM4) sometimes prevailed deliberately to ensure flexibility of the projects. This was also related to the organizational culture, as stated by one of the informants "[The relatively vague project charter occurred] because we have a hard time being concise on what we want. We keep it vague and keep room to play. It's a cultural aspect. We keep things vague because of flexibility. This practice is not encouraged by project management methods which require the development of a clear project charter and a structured plan, as admitted by the informant "Vague project charters are not good because in the end, someone has to make a decision. If the business side does not make a decision, IT will. In IT, they only have to choose between $a 0$ and $a$ I. If the business people do not make a decision, it's up to IT which knows less about business. It is suggested that employing project management methods should lessen the problem. In certain cases, the vagueness of the project charters needs to be clarified and refined iteratively; otherwise, the initial problem of equivocality may grow larger. Examples of this issue are undefined and conflicted project goals at the beginning of projects. Later on, unresolved equivocality may lead to different perceptions or interpretations toward information surrounding the projects, which will create difficulty to ascertain the 
project status or condition. One of the informants described "The decision-makers come from the different departments, I have just discussed [the project status and condition] and they have different goals. This particular project started from a technical point of view, the implementation should not have been carried out by the technical part of the organization, resulting in severe business implications".

Second, the ineffective communication (CPM3) seemed to be the result of different perceptions, priorities, roles and responsibilities among people in the project management structure, as well as the result of having large-scale projects. One of the informants stated "[the ineffective communication was occurred] because of the large time scale of this implementation, different people with different opinions were involved". Another informant stated "There are a lot of levels and different groups, teams and department. It's not always in our (business side) but also in the application and technology side. All those teams and persons have a place in the product development and should be heard at least". In this case, teambuilding, involvement and engagement are recommended to intensify the communicative atmosphere and cope with the problem, as one of the informants suggested "the solution is teambuilding; team building events, team time-outs, all kind of extra activities to really form a joint group". Another informant commented "Keep everyone involved. Be open in your communication". Good practice of communication was suggested, as one of the informants commented "You try to inform people. Newsletters and information on intranet are important. It is important to state the scope of the project. Communication works".

Third, the backdrop of lacking complementary skill and abilities among decision-makers (DFR2) in projects evaluations was attributed to the distinct professional experience within decision-makers or evaluators. One of the informants stated "They [the decision-makers] were quite different because the CEO was from sales; the CFO was a corporate controller. Their thoughts were not always $100 \%$ in the same direction". This issue seems also leading to one of the equivocal situation characteristics, i.e. the existence of diverse or lack of knowledge. Later on, decision-makers were compelled to exchange opinions, share meanings and beliefs towards the projects. One of the informants stressed "Rather than trying [to bridge the difference in opinions and meanings] and understand one another, they realized that it was not just the case. Knowledge that [was] different exist". In this case, decision-makers are suggested and encouraged to create and compromise the solutions for the projects' next course of actions [42] as well as nurturing solid awareness to further cope with such issue, instead of discovering the problems encountered in the evaluations.

Forth, unavailability of the requisite data to proceed with effective evaluations and to support decision-making (LED2) was attributed to several governance issues. Projects involving multiple stakeholders and parties were suspected to suffer such issues. One of the informants described "The project team consisted of those three types of people: [name of the first party], [name of the second party] and external consultants. We only have the external component as a measure of how much effort went into the project. So we captured too little data on the project itself in order for us to learn". Provision of the data for project evaluations was also affected by the unwillingness to inform negative reports known as the "mum effect" [56] as explained by one of the informants "The program delivery manager was the supplier. They did not want to give all the information to the project manager or the customer because then we knew exactly how much delay they had in their projects". Moreover, it appears that the process of collecting the data and reproducing it in appropriate form was time and resource consuming as stated by one of the informants "The problem is not the insufficient data but a lack of resources. And the lack of resources gives insufficient data". Besides the aforementioned suggestions to use project management methods and good practice of communication, the other identified ways to cope with the issues includes forming a solid steering committee and a standardized data. One of the informants commented "Every company and subsidiary has its own thoughts about it [the project and the data] and first you need some global rules from the head office saying this and this information is the standard one."

Finally, two informants commented on the use of project management methods, such as PRINCE 2 and PINO, and recommended the deployment of such methods to lessen the emergence of problems that lead to equivocal situations in project evaluations. One of the informants who experience a terminated project suggested "Sticking to the project management method guarantees success. Write your business case. Estimate the number of people, time and resources you need. Define the desired outcome of the project. Structure the project". Another informant who experience an escalated project commented "I am convinced that if we had used PRINCE 2 as a method to run this project, we would have terminated the project in a much earlier stage. If we would have updated the business case, we 
would eventually see that this is not a viable business case for the rest of the project. The project manager made all the products required by PRINCE 2, but they were not used the way it was meant to be".

\section{Discussion}

Our empirical data shows significant positive relationships between the three factors and the equivocal situations, which also confirm all the hypotheses. The result implies that the factors and the indicators within them are associated to the occurrence of equivocal situations in IS/IT project evaluations. The model demonstrates a moderate level of $\mathrm{R}^{2}$ and an acceptable predictive relevance and performance.

Conceivably, we suggest taking the indicators of these factors into account during project execution and before embarking on evaluations. High equivocality in project evaluations is suspected driving the projects to unwarranted escalation and premature termination.

The formative measurement allows for individual indicators assessment that identifies what are the salient problems within each of the factors. Distinct impacts among problems on the occurrence of equivocal situations are provided in the analysis. Positive effects of the factors mean that lessening specific problems within the suggested factors will help organizations to forestall the prevailing of equivocal situations in project evaluations.

The problems which have significant results include (1) improper planning of the project, specifically inadequately set out project milestones (CPM1); (2) improper controlling of the project, specifically inadequate control form senior management (CPM2); (3) the vagueness of project charter as the basis for managing the project (CPM4); (4) difficulty in gaining a mutual perception due to different backgrounds (DFR1); (5) the lack of complementary skill and abilities among decisionmakers to proceed with effective evaluations (DFR2); and, (6) unavailability of data to support the evaluations and decision-making (LED2). However, several impacts of these problems seem diverse across distinct groups of public versus private sector and high ladder versus low ladder projects. Extra attention to these specific problems should be given to projects which fall within these groups. For instance, senior management devotion to control and keep the projects on track is of utmost importance in high ladder project compared to other problems affecting equivocal situations in project evaluations.
Findings from our post hoc interviews with the project stakeholders suggest some relevant issues for practitioners. The five pointers suggest additional insights which need to be considered to cope with the occurrence of equivocal situations in project evaluations, for instance adherence to the project management methods, good practice of communication, and developing a solid steering committee.

\section{Conclusion}

This study offers meaningful contributions to research and practice. The utilized mixed-method connects the power of quantitative findings and the strength of qualitative explanations; thus, the study gains more valuable insights [57]. From a theoretical perspective, the study extends the relevance of decision dilemma theory and its application within the information system domain. The study contributes to the development of a model that highlights the essential factors to predict the occurrence of equivocal situations in IS/IT project evaluations.

In a practical sense, the study uncovers the salient drivers of equivocal situations. People in the project management structure and decision-makers as evaluators need to be aware of the characteristics of equivocal situations in project evaluations. To lessen the chance confronting the dilemmatic situations, this study suggests establishing a well-thought-out project management strategy. Such strategy should comprise of well-defined project milestones and project charters, and promote a strong and persistence control from top management. Commitment and involvement of top management are encouraged to make sure valuable evaluations are conducted and proper continuation decisions are taken. The findings also suggest taking into account the diversity of backgrounds, skill, and abilities of the decisionmakers in order to be able to proceed with effective evaluations. Maintaining and assuring the availability of requisite data for evaluation should also lessen the chance of getting into equivocal situations.

Moreover, attention should also be given into which sector (public versus private) and which types of the IS/IT projects (high versus low project evaluation ladder) are being executed, as the impacts of each problems are varied within the two groups. It is highly important to lessen the equivocal situations when dealing with large-scale IS/IT projects in order to prevent the occurrence of rare and unpredictable events during project executions.

Limitation entailed in this study concerns with the way the data was gathered, which makes the results 
may not be generalizable. The relatively small sample in the multi-group analysis may hamper the computation and the result as well. Thus, the need to obtain larger sample in further studies is critical in order to be able to generalize the findings. Moreover, in-depth further examinations on each significant problem are also warranted.

\section{References}

[1] Charette, R.N., "Why Software Fails [Software Failure]", Spectrum, IEEE, 42(9), 2005, pp. 42-49.

[2] Ewusi-Mensah, K., "Critical Issues in Abandoned Information Systems Development Projects", Communications of the ACM, 40(9), 1997, pp. 74-80.

[3] Sauer, C., Liu, L., and Johnston, K., "Enterprise-Level Project Management Capabilities: A Comparison of the Construction and It Services Industries", Proceedings of the 20th International Conference on Information Systems, 1999 , pp. 440-445

[4] Keil, M., and Flatto, J., "Information Systems Project Escalation: A Reinterpretation Based on Options Theory", Accounting, Management and Information Technologies, 9(2), 1999, pp. 115-139.

[5] Kipp, A., Riemer, K., and Wiemann, S., "It Mega Projects: What They Are and Why They Are Special. Ecis 2008 Proceedings. Paper 152."2008

[6] Buhl, H., "The Contribution of Business and Information Systems Engineering to the Early Recognition and Avoidance of "Black Swans" in It Projects", Business \& Information Systems Engineering, 4(2), 2012, pp. 55-59. [7] Buhl, H., and Meier, M., "The Responsibility of Business and Information Systems Engineering in LargeScale It Projects", Business \& Information Systems Engineering, 3(2), 2011, pp. 61-64.

[8] Lee, J.S., Keil, M., and Kasi, V., "The Effect of an Initial Budget and Schedule Goal on Software Project Escalation", Journal of Management Information Systems, 29(1), 2012, pp. 53-78.

[9] Pan, S.L., Pan, G.S.C., Newman, M., and Flynn, D., "Escalation and De-Escalation of Commitment to Information Systems Projects: Insights from a Project Evaluation Model", European Journal of Operational Research, 173(3), 2006, pp. 1139-1160

[10] Farbey, B., Land, F., and Targett, D., "Moving Is Evaluation Forward: Learning Themes and Research Issues", Journal of Strategic Information Systems, 8(2), 1999, pp. 189-207.

[11] Farbey, B., Land, F., and Targett, D., "Evaluating Investments in It", Journal of Information Technology, 7(2), 1992, pp. 109.

[12] Irani, Z., Sharif, A.M., and Love, P.E.D., "Linking Knowledge Transformation to Information Systems Evaluation", European Journal of Information Systems, 14(3), 2005, pp. 213-228.

[13] Abdel-Hamid, T.K., Sengupta, K., and Ronan, D., "Software Project Control: An Experimental Investigation of Judgment with Fallible Information", IEEE Transactions on Software Engineering, 19(6), 1993, pp. 603-612.
[14] Mähring, M., and Keil, M., "Information Technology Project Escalation: A Process Model*", Decision Sciences, 39(2), 2008, pp. 239-272.

[15] Snow, A.P., and Keil, M., "The Challenge of Accurate Software Project Status Reporting: A Two-Stage Model Incorporating Status Errors and Reporting Bias", IEEE Transactions on Engineering Management, 49(4), 2002, pp. 491-504.

[16] Snow, A.P., and Keil, M., "A Framework for Assessing the Reliability of Software Project Status Reports", Engineering Management Journal, 14(2), 2002, pp. 20.

[17] Smithson, S., and Hirschheim, R., "Analysing Information Systems Evaluation: Another Look at an Old Problem", European Journal of Information Systems, 7(1998, pp. 158-174.

[18] Irani, Z., "Information Systems Evaluation: Navigating through the Problem Domain", Information \& Management, 40(1), 2002, pp. 11-24.

[19] Bannister, F., and Remenyi, D., "Acts of Faith: Instinct, Value and It Investment Decisions", Journal of Information Technology (Routledge, Ltd.), 15(3), 2000, pp. 231-241.

[20] Bragger, J.D., Bragger, D., Hantula, D.A., and Kirnan, J., "Hyteresis and Uncertainty: The Effect of Uncertainty on Delays to Exit Decisions", Organizational Behavior and Human Decision Processes, 74(3), 1998, pp. 229-253.

[21] Bragger, J.D., Hantula, D.A., Bragger, D., Kirnan, J., and Kutcher, E., "When Success Breeds Failure: History, Hysteresis, and Delayed Exit Decisions", Journal of Applied Psychology, 88(1), 2003, pp. 6-14.

[22] Sleesman, D.J., Conlon, D.E., Mcnamara, G., and Miles, J.E., "Cleaning up the Big Muddy: A Meta-Analytic Review of the Determinants of Escalation of Commitment", The Academy of Management Journal, 55(3), 2012, pp. 541-562.

[23] Bowen, M.G., "The Escalation Phenomenon Reconsidered: Decision Dilemmas or Decision Errors?", The Academy of Management Review, 12(1), 1987, pp. 5266

[24] Brockner, J., "The Escalation of Commitment to a Failing Course of Action: Toward Theoretical Progress", The Academy of Management Review, 17(1), 1992, pp. 3961

[25] Carson, S.J., Wu, T., and Moore, W.L., "Managing the Trade-Off between Ambiguity and Volatility in New Product Development", Journal of Product Innovation Management, 29(6), 2012, pp. 1061-1081.

[26] Watts Sussman, S., and Guinan, P.J., "Antidotes for High Complexity and Ambiguity in Software Development", Information \& Management, 36(1), 1999, pp. 23-35.

[27] Daft, R.L., and Macintosh, N.B., "A Tentative Exploration into the Amount and Equivocality of Information Processing in Organizational Work Units", Administrative Science Quarterly, 26(2), 1981, pp. 207224.

[28] Lim, K.H., and Benbasat, I., "The Effect of Multimedia on Perceived Equivocality and Perceived Usefulness of Information Systems", MIS Quarterly, 24(3), 2000, pp. 449-471. 
[29] Keil, M., and Robey, D., "Turning around Troubled Software Projects: An Exploratory Study of the Deescalation of Commitment to Failing Courses of Action", Journal of Management Information Systems, 15(4), 1999, pp. 63-87.

[30] Gemino, A., Reich, B., and Sauer, C., "A Temporal Model of Information Technology Project Performance", Journal of Management Information Systems, 24(3), 2007, pp. 9-44.

[31] Hartman, F., and Ashrafi, R.A., "Project Management in the Information Systems and Information Technologies Industries", Project Management Journal, 33(3), 2002, pp. 5.

[32] Keil, M., Rai, A., Cheney Mann, J.E., and Zhang, G.P., "Why Software Projects Escalate: The Importance of Project Management Constructs", Engineering Management, IEEE Transactions on, 50(3), 2003, pp. 251261.

[33] Schultz, C., Salomo, S., De Brentani, U., and Kleinschmidt, E.J., "How Formal Control Influences Decision-Making Clarity and Innovation Performance", Journal of Product Innovation Management, 30(3), 2013, pp. 430-447.

[34] Frishammar, J., Floren, H., and Wincent, J., "Beyond Managing Uncertainty: Insights from Studying Equivocality in the Fuzzy Front End of Product and Process Innovation Projects", IEEE Transactions on Engineering Management, 58(3), 2011, pp. 551-563.

[35] Daft, R.L., Lengel, R.H., and Trevino, L.K., "Message Equivocality, Media Selection, and Manager Performance Implications for Information-Systems", MIS Quarterly, 11(3), 1987, pp. 355-366.

[36] Levander, E., Engström, S., Sardén, Y., and Stehn, L., "Construction Clients' Ability to Manage Uncertainty and Equivocality", Construction Management and Economics, 29(7), 2011, pp. 753-764.

[37] Simons, T., Pelled, L.H., and Smith, K.A., "Making Use of Difference: Diversity, Debate, and Decision Comprehensiveness in Top Management Teams", The Academy of Management Journal, 42(6), 1999, pp. 662 673.

[38] Pelled, L.H., Eisenhardt, K.M., and Xin, K.R., "Exploring the Black Box: An Analysis of Work Group Diversity, Conflict, and Performance", Administrative Science Quarterly, 44(1), 1999, pp. 1-28.

[39] Lee, G., and Xia, W., "Toward Agile: An Integrated Analysis of Quantitative and Qualitative Field Data on Software Development Agility", MIS Quarterly, 34(1), 2010, pp. 87-114.

[40] Van Doorn, S., Jansen, J.J.P., Van Den Bosch, F.a.J., and Volberda, H.W., "Entrepreneurial Orientation and Firm Performance: Drawing Attention to the Senior Team", Journal of Product Innovation Management, 30(5), 2013, pp. 821-836.

[41] Newman, M., and Sabherwal, R., "Determinants of Commitment to Information Systems Development: A Longitudinal Investigation", MIS Quarterly, 20(1), 1996, pp. 23-54.

[42] Brun, E., and Saetre, A.S., "Ambiguity Reduction in New Product Development Projects", International Journal of Innovation Management, 12(04), 2008, pp. 573-596.
[43] Karimi, J., Somers, T.M., and Gupta, Y.P., "Impact of Environmental Uncertainty and Task Characteristics on User Satisfaction with Data", Information Systems Research, 15(2), 2004, pp. 175-193.

[44] Gattiker, T.F., and Goodhue, D.L., "What Happens after Erp Implementation: Understanding the Impact of Interdependence and Differentiation on Plant-Level Outcomes", MIS Quarterly, 29(3), 2005, pp. 559-585.

[45] Moore, G.C., and Benbasat, I., "Development of an Instrument to Measure the Perceptions of Adopting an Information Technology Innovation", Information Systems Research, 2(3), 1991, pp. 192-222.

[46] Hair, J.F., Hult, G.T.M., Ringle, C.M., and Sarstedt, M., A Primer on Partial Least Squares Structural Equations Modeling (Pls-Sem), SAGE, Thousand Oaks, 2014.

[47] Ringle, C.M., Sarstedt, M., and Straub, D.W., "A Critical Look at the Use of Pls-Sem in Mis Quarterly", MIS Quarterly, 36(1), 2012, pp. III-XIV.

[48] Ringle, C.M., Wende, S., and Will, S., "Smartpls 2.0 (M3) Beta, Hamburg", in (Editor, 'ed.'^'eds.'): Book Smartpls 2.0 (M3) Beta, Hamburg, 2005

[49] Hair, J.F., Ringle, C.M., and Sarstedt, M., "Pls-Sem: Indeed a Silver Bullet", Journal of Marketing Theory \& Practice, 19(2), 2011, pp. 139-152.

[50] Hair, J., Anderson, R., Tatham, R., and Black, W., Multivariate Data Analysis: A Global Perspective, Prentice hall Upper Saddle River, NJ, 7th Edition edn, 2010.

[51] Andreev, P., Heart, T., Maoz, H., and Pliskin, N., "Validating Formative Partial Least Squares (Pls) Models: Methodological Review and Empirical Illustration", 2009,

[52] Petter, S., Straub, D., and Rai, A., "Specifying Formative Constructs in Information Systems Research", MIS Quarterly, 31(4), 2007, pp. 623-656.

[53] Mohan, L., Holstein, W.K., and Adams, R.B., "Eis: It Can Work in the Public Sector", MIS Quarterly, 14(4), 1990, pp. 435-448.

[54] Rocheleau, B., and Wu, L., "Public Versus Private Information Systems: Do They Differ in Important Ways? A Review and Empirical Test", The American Review of Public Administration, 32(4), 2002, pp. 379-397.

[55] Farbey, B., Land, F.F., and Targett, D., "A Taxonomy of Information Systems Applications: The Benefits' Evaluation Ladder", European Journal of Information Systems, 4(1), 1995, pp. 41-50.

[56] Smith, H.J., Keil, M., and Depledge, G., "Keeping Mum as the Project Goes Under: Toward an Explanatory Model", Journal of Management Information Systems, 18(2), 2001, pp. 189-227.

[57] Creswell, J.W., Research Design : Qualitative, Quantitative, and Mixed Method Approaches, Sage Publications, Thousand Oaks, Calif., 2003. 